\title{
PARAMETRIC COMPARISON OF COMBUSTION PERFORMANCE BETWEEN TWO DIFFERENT PISTON HEAD CONFIGURATIONS FOR DIESEL ENGINES USING NUMERICAL SIMULATIONS
}

\author{
SHOUVIK BANDOPADHYAY, SOUMYAJEET DEY, ABHIJOY GANGULY \\ \& NISHCHAY SHAILESH SADRANI \\ Department of Aerospace Engineering, SRM Institute of Science and Technology, Tamil Nadu, India
}

\begin{abstract}
In the present work, a full scale computational analysis is performed inside the combustion chamber of a heavy duty industrial diesel engine for two different piston head configurations namely the Open $W$ type and the Omega type. The complete domain is converted into a sector of 60 degrees as the combustion chamber is axi-symmetric consists of 6 nozzles located at the top centre. The extracted sector is enabled with dynamic computational grid control consisting of a baseline computational grid of $0.004 \mathrm{~m}$ with suitable adaptive refinements and embeddings to capture the various physical phenomena happening simultaneously inside the chamber. Appropriate physical models are set in place in order to model fuel atomization, turbulent dispersion, and air fuel mixing, evaporation, and vapourization, combustion and flame propagation. A transient simulation is performed for both the piston configurations. The two piston head configurations are compared on the basis of Indicated Mean Effective Pressure (IMEP), Mean Temperature, Integrated Heat Release, Integrated Heat Release Rate, Work Done and Emissions released for the same range of crank angles. It was found out that the performance parameters for both the piston configurations are fundamentally influenced by the fuel spray length for each of the piston type.
\end{abstract}

KEYWORDS: Fuel Injection and Spray Modeling \& Governing Physics

Received: Jun 09, 2020; Accepted: Jun 29, 2020; Published: Sep 21, 2020; Paper Id.: IJMPERDJUN20201373

\section{INTRODUCTION}

Modern day internal combustion engines available in the marketplace for automobiles or even light aviation use may be commercially classified as petrol engines and diesel engines. Thermodynamically, the working and performance of the petrol engines and the diesel engines are characterized by the Otto cycle and the Diesel Cycle respectively. Although the said thermodynamic cycles give a linear analytical model to analyze the working of engines, practical scenarios are extremely difficult and crucial to study. Reasons vary from fundamental understanding of the ongoing physics of the operation to design optimization for improved performance or efficiency.

Several physical phenomena occur inside an internal combustion engine, more precisely the engine combustion chamber during its operation. Fuel atomization, mixing of air and fuel, reacting flows, combustion, turbulence and associated instabilities like the Kelvin-Helmholtz instability and the Rayleigh Taylor instability are to name a few. All these physical processes are engineered to occur inside an engine combustion chamber and after significant losses of energy, avail the user with some available power as output which may be converted to useful work, i.e. motion. The overall operations also emit sound and gases which may be pollutants.

For any internal combustion engine, its piston is an integral component. The piston shape and configuration 
utilized in an internal combustion engine directly influence most, if not all the governing physics and thereby critical performance parameters associated with the operation of the engine. Therefore it becomes of principal importance to study the effects on the governing physics during the operation of the engines inside the engine combustion chamber with different piston configurations. However, as everything happens inside an entity, i.e., the combustion chamber which is not visible to directly by our naked eyes, computational analyses become the most feasible method of study. Such a study before the actual mass production of the engines will ensure lesser errors and enhanced performance of the engines. Among the various types of piston configurations available in the marketplace, the Omega type piston and the Open W type piston configuration are most popular ones.

The current study precisely involves the comparison of the two above mentioned piston configurations on their physical and performance parameters with the aid of numerical simulation using commercially available software known as CONVERGE CFD Studio. The engine used as a reference for the current simulation is an actual heavy duty diesel engine with 6 nozzle configuration known as the $C A T-3410$ by The Caterpillar Inc. The said engine is utilized for a variety of engine applications.

In any diesel engine, the fuel is transferred in the combustion chamber via injection with the means of a nozzle. The fuel is sprayed into the chamber which is then subjected to dissociate and atomize prior to mixing with air. Then the chemical reaction of combustion occurs. Differences in piston head configuration influence the combustion process and thereby the engine performance. Air mixes with fuel in the combustion chamber when the piston is at the Top Dead Centre (TDC). Thus, combined flow in swirl and the flow in the radial direction from the piston crown, both must be considered for a proper in depth study. Needless to say, said flow of air and fuel is greatly influenced by the shape of the piston head. A close cycle simulation is executed for the current study which implies that all the valves of the engine are closed and only two strokes, namely the compression and combustion strokes are considered as the engine operation throughout the simulation.

\section{GEOMETRY}

The current engine used for the simulation has a 6 nozzle injector located in the centre of the engine. Also, the cylindrical shape of the combustion chamber makes the geometry axi-symmetric. The engine can therefore be divided into 6 identical sectors each containing one nozzle. All physical phenomena taking place in one sector will be nearly identical to the phenomena in the other engine sectors and hence the entire engine, Hence, in order to save computational time, only one engine sector of 60 degrees is studied. The geometry profiles are created with Make Engine surface Tool in Converge. For the Open W piston the surface profiles are extracted and the sector is subsequently created from the bowl profile whereas for the Omega piston, the sector is created using the bowl profile.

The values for the basic specified engine parameters for the current reference engine are mentioned in the table 1, given below.

Table 1: Basic Engine Parameters

\begin{tabular}{|l|c|}
\hline \multicolumn{1}{|c|}{ Parameter } & Value \\
\hline Bore & $0.13176 \mathrm{~m}$ \\
\hline Stroke & $0.1651 \mathrm{~m}$ \\
\hline Rod & $0.263 \mathrm{~m}$ \\
\hline RPM & 1600 \\
\hline Compression Ratio & 17.5 \\
\hline
\end{tabular}


Figure 1, given below represents the geometry of the combustion chamber and the two different piston head configurations. The nozzle from the injector may be seen indicated with the white arrow head and is positioned at the origin for both the piston head configurations. The geometry may be seen composed of triangular faces throughout owing to the fact that the default element in CONVERGE CFD Studio is triangle.

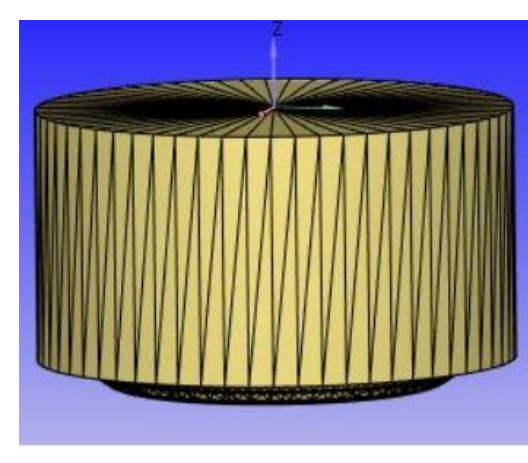

(a) Combustion Chamber Front View

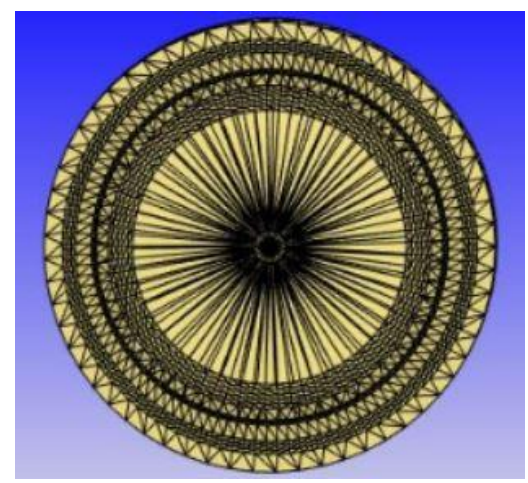

(b) Combustion Chamber Top View

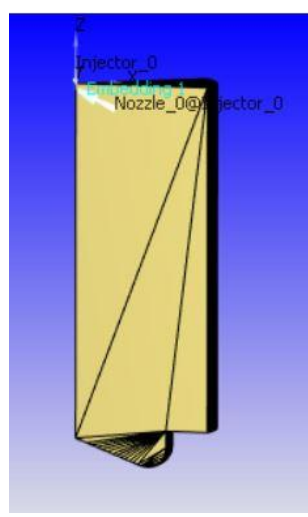

(c) Omega Piston

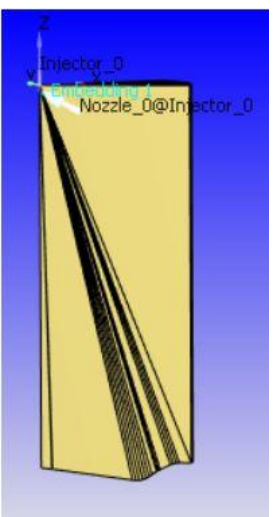

(d) Open WPiston

Figure 1: Combustion Chamber Geometry and Piston Configurations.

Needless to say, the initial geometry of the combustion chamber was checked for any and all errors. No errors were found. Same was repeated after creating and extracting the sectors. Once again, there weren't any geometrical errors. It is important to note that the focus of the study lies in what happens inside the combustion chamber only and hence other parts of the engine are excluded from the simulation. Once the geometry preparation was completed, the model is divided into regions and supplied with appropriate initial and boundary conditions.

\section{GOVERNING EQUATIONS, INITIAL CONDITIONS AND BOUNDARY CONDITIONS}

The equation of continuity, momentum, energy, equation of state and species transport equations are solved in 3 dimensions with appropriate initial and boundary conditions. $\mathrm{C}_{7} \mathrm{H}_{16}$ (Heptane) is used as the diesel fuel. Gas Simulation is selected with Diesel2 option as the parcel for spray modeling in combustion. The simulation runs from crank angle of -147 degrees to 135 degrees. The table 2 below summarizes the different initial and boundary conditions applied for the current simulation.

Table 2: Initial Conditions and Boundary Conditions

\begin{tabular}{|c|c|c|c|c|}
\hline \multicolumn{5}{|c|}{ Initial Conditions } \\
\hline Boundary Name & Temperature & Pressure & Mass Fraction & Molecular Weight \\
\hline \multirow{4}{*}{ In cylinder region } & \multirow{4}{*}{$355 \mathrm{~K}$} & \multirow{4}{*}{$197000 \mathrm{~Pa}$} & $\mathrm{O}_{2}: 0.23029$ & 31.998 \\
\hline & & & $\mathrm{N}_{2}: 0.76765$ & 44.01 \\
\hline & & & $\mathrm{CO}_{2}: 0.0014304$ & 18.01528 \\
\hline & & & $\mathrm{H}_{2} \mathrm{O}: 0.00062960$ & 28.0134 \\
\hline \multicolumn{5}{|c|}{ Boundary Conditions } \\
\hline Boundary Name & Type & Motion & Details & Temperature \\
\hline Piston & Wall & Moving & Piston Motion & $533 \mathrm{~K}$ \\
\hline Front Face & Periodic & Stationary & Sector (60 degrees) & \multirow{2}{*}{ Matching Boundaries } \\
\hline Back Face & Periodic & Stationary & Sector (60 degrees) & \\
\hline Cylinder Wall & Wall & Stationary & N.A. & $433 \mathrm{~K}$ \\
\hline Cylinder Head Wall & Wall & Stationary & N.A. & $523 \mathrm{~K}$ \\
\hline
\end{tabular}


The periodic boundary condition is set up as the sector geometry is only a part of a 360 degree cylinder. While the simulation runs, Converge reads the keyword match and then copies the value of each boundary condition, of the first periodic boundary to its matching boundary.

\section{PHYSICAL MODELS}

\subsection{Fuel Injection and Spray Modeling}

$2.7016 * 10^{-5} \mathrm{Kg} \mathrm{C}_{7} \mathrm{H}_{16}$ (Heptane) injection is modeled as Lagrangian spray parcels with the aid of a 9 degree spray cone angled nozzle of $259 \mu \mathrm{m}$ diameter and $129.5 \mu \mathrm{m}$ injection radius in the combustion chamber in cyclic mode for a period of 720 degrees in total. Parcels are made to spread evenly throughout the cone. Turbulent dispersion and evaporation phenomena are modeled with the aid of O'Rourke model and the Frossling model respectively. Frossling model also allows modeling the effects of the fuel getting evaporated into its pure vapour form. The mass fraction of the liquid is 0.97 with bin size of $0.001 \mathrm{~m}$ and the minimum vapour mass fraction per cell being 0.001 . The parcels of the fuel can collide only with other parcels within the same cell. This leads to mesh sensitivity. Therefore to remove the effects of grid sensitivity, NTC collision model with post collision outcomes option is selected. For a droplet of fuel, the drop coefficient influences the variation in the shape of the droplet. To capture any distortion in the droplets of the fuel, the Dynamic Drop Drag model is invoked. It's an obvious fact that the fuel sprayed into the combustion chamber will collide and interact with the internal cylindrical wall of the chamber. Droplets are made to slide on the wall or rebound off them when that happens in the present simulation model The fuel injection starts at -9 degrees and the injection duration is 21 degrees. For the current simulation, the nozzle is located at (0, 0, -0.0032208) Cartesian coordinates. Rayleigh Taylor model and Kelvin-Helmholtz model are used as the injection models. The mass flow rate of the fuel with varying crank angles can be seen in the figure 2.

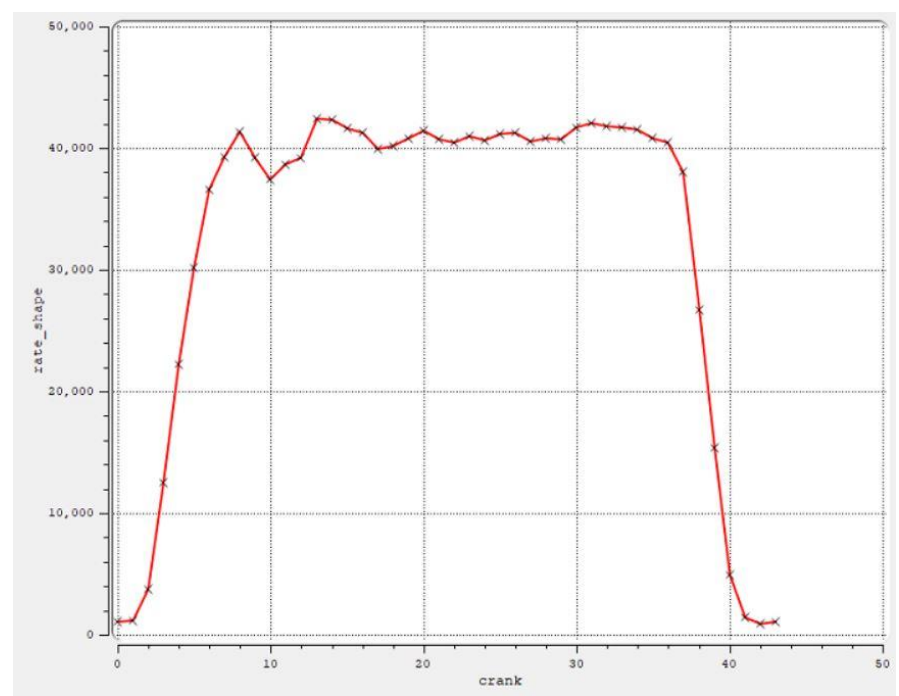

Figure 2: Mass Flow Rate of the Fuel Spray with Varying Crank Angles.

\subsection{Combustion Modeling and Turbulence Modeling}

SAGE detailed chemistry solver with CVODES is used for the present work due to its capability to resolve ignition and laminar flame propagation accordingly. The temporal type is sequential. The minimum cell temperature and the minimum no. of hydrocarbon species are increased in order to decrease the number of cells in which combustion is supposed to take place with their values being $600 \mathrm{~K}$ and $1 \mathrm{e}-8$ respectively. Incomplete combustion may occur in the event when there aren't enough hydrocarbons in a cell. The combustion starts at -10 degrees and ends at 135 degrees. Extended Zeldovich $N O_{X}$ 
model and Hiroyasu Soot model are set in place for monitoring emissions. The turbulence is modeled by the RNG $k-\varepsilon$ model.

\section{SIMULATION RUNTIME PARAMETERS AND GRID CONTROL}

The simulation is inherently a transient crank angle based engine simulation that starts at -147 degrees and ends at 135 degrees. $5 * 10^{-7}$ Seconds is the initial time step with minimum and maximum time steps being $1 * 10^{-8}$ seconds and $2.5 *$ $10^{-5}$ seconds respectively. PISO scheme is implemented to solve the Navier Stokes equation.

The baseline grid size for the present simulation is $0.0014 \mathrm{~m}$ in $\mathrm{x}, \mathrm{y}$ and $\mathrm{z}$ directions. Apart from the baseline grid, sequential mesh embedding of scale factor $2\left(R_{1}=0.001 \mathrm{~m} ; \mathrm{R}_{2}=0.003 \mathrm{~m} ; \mathrm{L}=0.01 \mathrm{~m}\right)$ is implemented for the nozzle starting from -10 degrees till 15 degrees in order to satisfactorily compute the fuel spray. A single layer sequential embedding of scale factor 1 is also implemented on the piston and cylinder head starting from -20 degrees till 180 degrees. Two different adaptive mesh refinements of level 2 are also implemented. The first a velocity based permanent AMR of SGS 2 and the second a temperature based sequential (-12 to 180) of SGS 5. Figure 3 shows the simulation grid for both the piston head configurations at TDC and BDC.

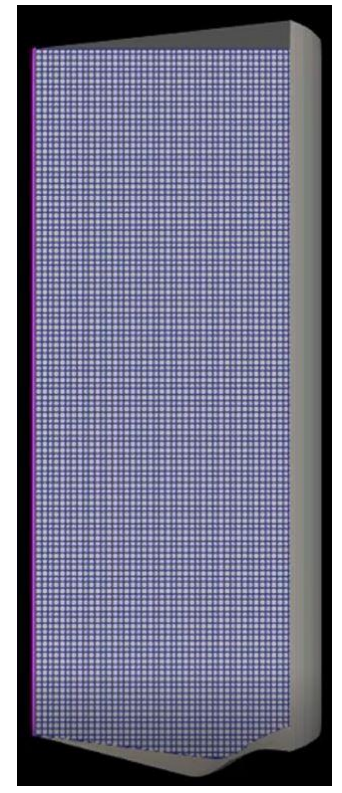

(a) Open W Piston at BDC

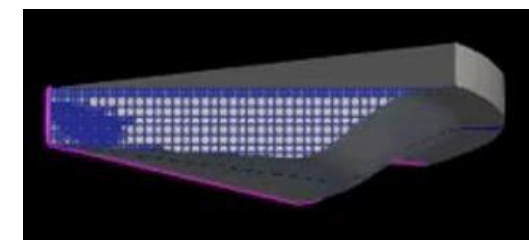

(b) Open W Piston at TDC

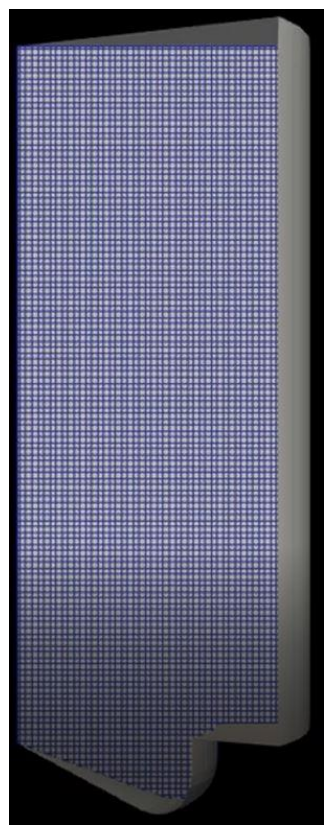

(c) Omega Piston at BDC

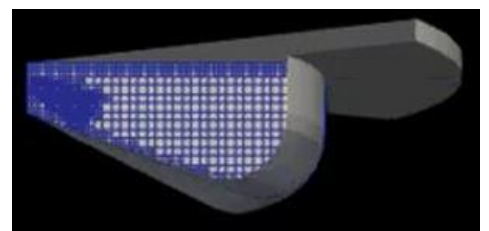

(d) Omega Piston at TDC

Figure 3: Simulation Grids at BDC \& TDC for Both Piston Configurations.

\section{RESULTS AND DISCUSSIONS}

\subsection{Parametric Analysis}

The Figure 4 illustrates various parameters of the engine against the engine crank angle. It can be observed in the Figure 4(a) that, volume curves for both the piston head configurations are coinciding with each other. This is consistent with the fact that the compression ratio in both the cases is same.

Figure 4(b) provides evidence for the Indicated Mean Effective Pressure (IMEP) of the engine. IMEP is the gauge of the output work for swept volume of engine. Being independent of displacement, no. of cylinders and speed, it is the primary parameter for finding efficiency of the engine. It is clear from the figure that Omega type piston head has higher 
value of IMEP compared to the Open W Type piston head for the same engine.

Figure 4(c) provides information about the mean temperature in the combustion chamber throughout the simulation against different crank angles. Mean temperature of the Omega Type piston head is $1767 \mathrm{~K}$ which is higher than that of the Open W-Type which is $1464 \mathrm{~K}$. This leads us to believe that there will be comparatively higher heat release in the combustion chamber with the Omega type piston head than that of the chamber with the Open W piston head. Furthermore, it can be concluded that the engine with Omega type piston has lower percentage of un-burnt fuel air mixture.

Figure 4(d) and figure 4(e) illustrate the Indicated Heat Release (IHR) and the Indicated Heat Release Rate (IHRR) respectively. The IHRR of the omega piston can be observed to be higher and as the same fuel is used in both the configurations with the same amount of injected mass, an inference can be drawn that the combustion efficiency of the omega piston is higher. The actual value of the IHR is higher for the Omega type piston for lower crank angles (0 to 50) but then the difference in the IHR values become very minimal as the engine cranks at higher angles.

Figure 4(f) speaks about the net work done by the engine for each of the piston head configuration. It is abundantly clear that the area under the curve for the omega piston head profile is greater than that of the Open $\mathrm{W}$ piston head profile.

Figure 4(g) and figure 4(h) speaks about the Carbon Monoxide and the Carbon Dioxide Production in the engine as by-products of the combustion. Carbon Dioxide are produced more in the variant with the Omega Piston for lower crank angles. As for carbon monoxide, the peak is greater for the Omega Piston but the quantity of the carbon monoxide produced plummets without more ado subsequent to its peak.

It is evident from the figure 4(i), figure 4(j) and figure 4(k) that while Omega piston head generates higher concentration of $\mathrm{NO}_{\mathrm{x}}$, soot formation and the quantity of un-burnt hydrocarbons is lesser in the same as compared to the Open $\mathrm{W}$ piston head configuration.

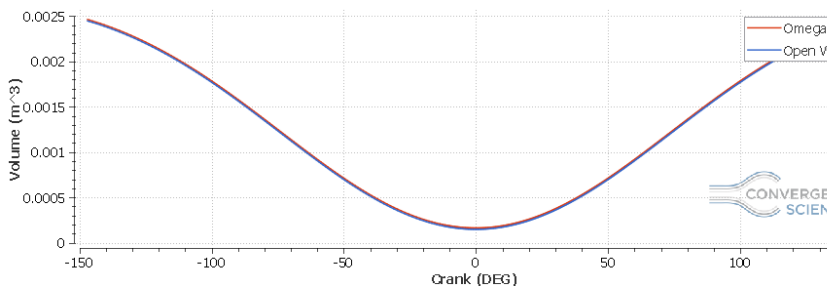

(a)Volume VS Crank Angle

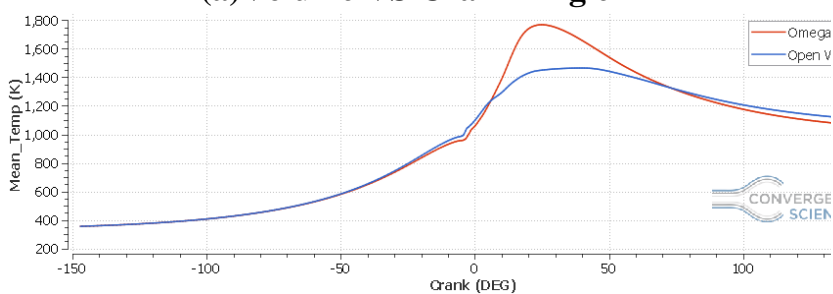

(c) Mean Temperature

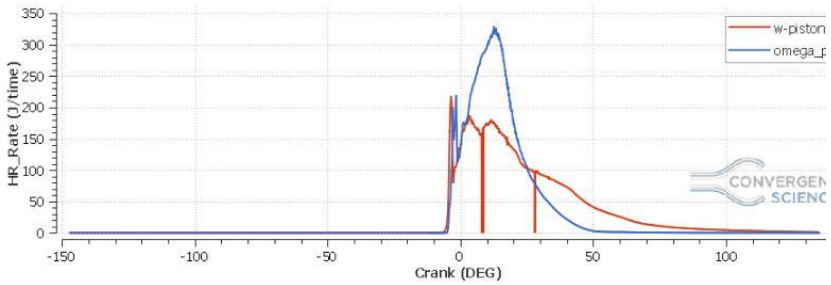

(e) Integrated Heat Release Rate

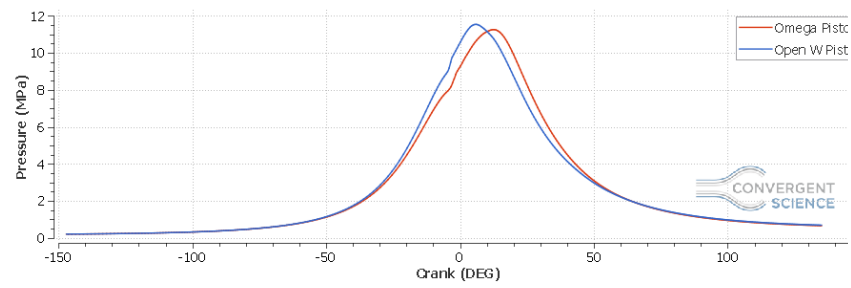

(b) IMEP

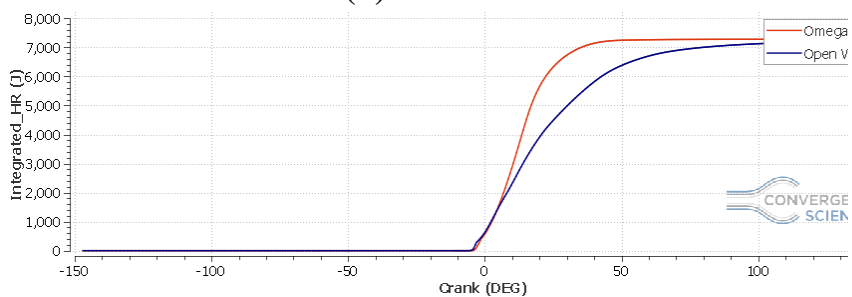

(d) Integrated Heat Release

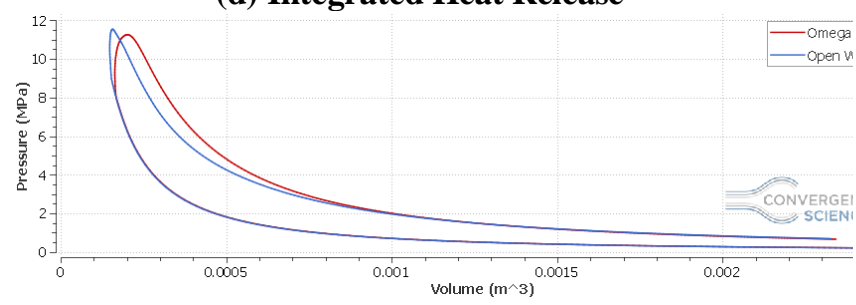

(f)Net Work Done 


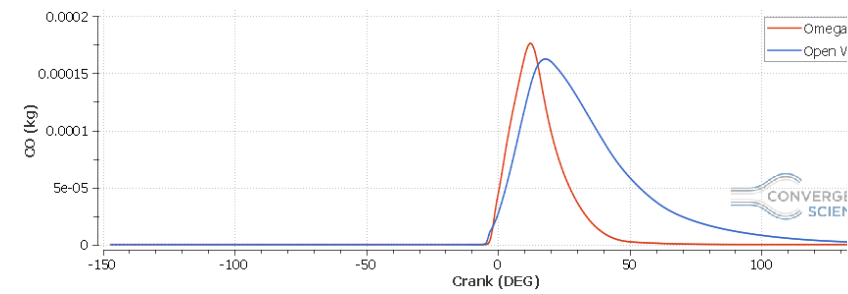

(g) Carbon Monoxide Emissions

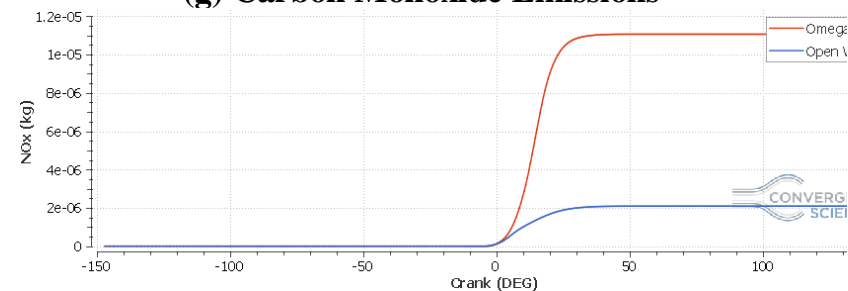

(i) $\mathrm{NO}_{\mathrm{x}}$ Concentrations

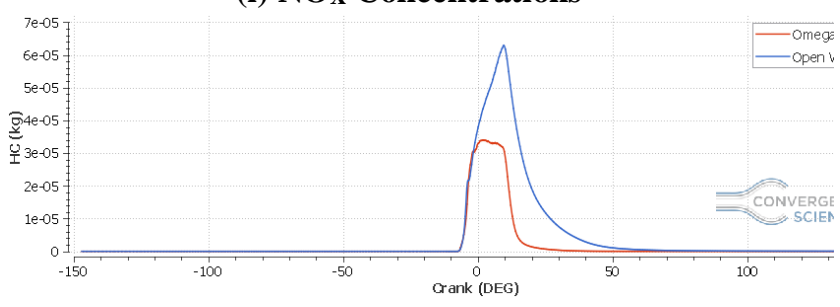

(k) Unburnt Hydrocarbons

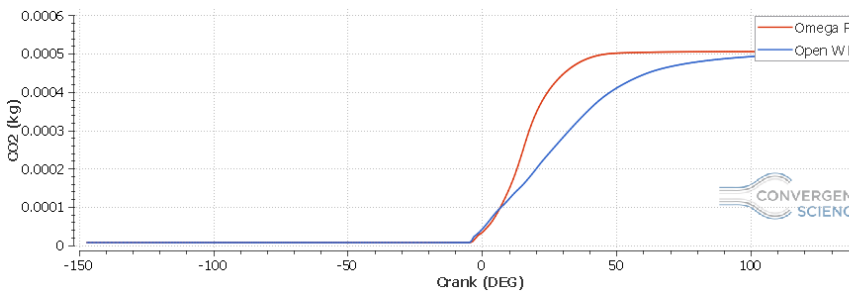

(h) Carbon Dioxide Emissions

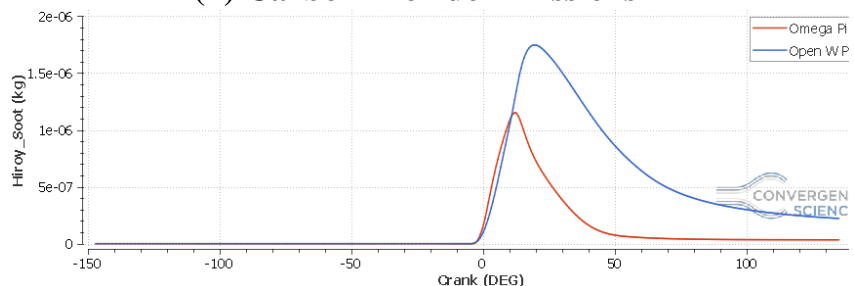

(j) Soot Formation

Figure 4: Simulation Outputs Comparing Performance of OpenW and Omega Piston Configurations.

Other parameters like the Torque and the Power Output can be compared with the aid of the Engine Calculator of the Converge. The table 3 below summarizes all the parameters of the engine for both the piston configurations.

Table 3: Summary of Engine Performance Parameters

\begin{tabular}{|c|c|c|c|c|}
\hline Parameter & Unit & Open W Piston & Omega Piston & $\begin{array}{c}\text { Percentage Increase } \\
\text { for Omega Piston } \\
\text { Keeping Value of } \\
\text { Omega Piston as the } \\
\text { Baseline } \\
\text { (Denominator) } \\
\end{array}$ \\
\hline Cranking Duration & Degrees & 270.156 & 270.171 & - \\
\hline Work & $\mathrm{N}-\mathrm{m}$ & 3028.53 & 3049.28 & $0.844 \%$ \\
\hline IMEP & bar & 12.4 & 13.96 & $11.175 \%$ \\
\hline IHR & $\mathbf{J}$ & 7107.87 & 7244.34 & $1.188 \%$ \\
\hline Power & $\mathrm{kW}$ & 107.77 & 121.32 & $11.169 \%$ \\
\hline Torque & $\mathrm{N}-\mathrm{m}$ & 642.78 & 724.075 & $11.23 \%$ \\
\hline \multicolumn{5}{|c|}{ Percentage of Combustion at Varying Crank Angles } \\
\hline $\begin{array}{c}\text { Percent of } \\
\text { Combustion } \\
\text { Completed Notation }\end{array}$ & Unit & Open W Piston & Omega Piston & Comment \\
\hline CA10 & Degrees & 0.70348 & 1.00833 & \multirow{3}{*}{$\begin{array}{l}\text { Overall, Combustion } \\
\text { happens faster for the } \\
\text { Omega Piston }\end{array}$} \\
\hline CA50 & Degrees & 17.8347 & 12.5019 & \\
\hline CA90 & Degrees & 53.0275 & 27.5283 & \\
\hline
\end{tabular}

\subsection{Governing Physics}

From the parametric analysis so far, it can be concluded that the Omega type piston head configuration gives better outputs in terms of the performance parameters. However, it is paramount to know the exact physics that governs the same. A fundamental approach would be to track the propagation of the fuel spray in combustion chamber for both the piston head 
configurations as displayed here in the figure 5 .

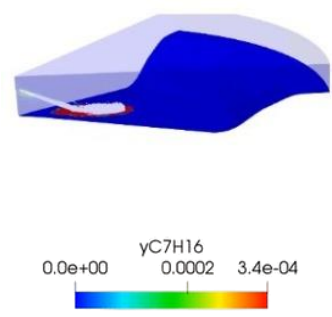

(a) Open W Piston Fuel Spray Injection
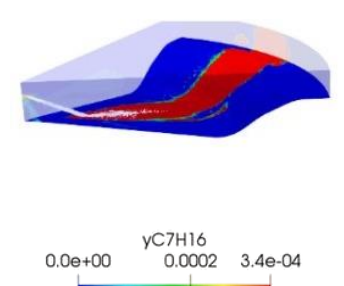

(b) Open W Piston Fuel

Spray Vapourization
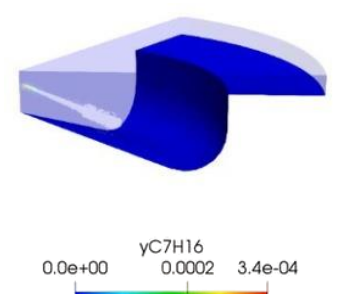

(c) Omega Piston Fuel Spray Injection
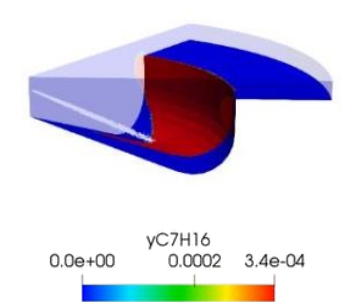

(d) Omega Piston Fuel Spray Vapourization

Figure 5. Fuel Spray Length and the Fuel Reception by Open W and Omega Piston Bowl Profiles

It is distinctly interpretable that the fuel spray length in the Omega type piston head configuration is greater than that of the Omega type piston head configuration even though the mass flow rate of the fuel spray and the injection nozzle configuration is same. Due to the presence of a greater elevation in the Open W piston, the fuel spray's entry angle becomes unsuited and hence it results in a decrease of the spray penetration length. This further leads the spray particles to attach to the bowl surface in the Open W piston due to its adhesion. As a result, the vapourization of the fuel is delayed leading to unburnt fuel particles which in turn results in soot formation and power loss.

\section{CONCLUSIONS}

- A full scale computational fluid dynamics model is created within CONVERGE CFD Studio software and systematic simulations of combustion and associated phenomena were performed to compare the overall performance of Open $\mathrm{W}$ type piston and Omega type piston head configurations.

- Simulations were only performed for the compression and the power stroke with the valves assumed to be always closed. A sector analysis model was adapted in order to reduce the total time of computation.

- An adaptive computational grid with necessary embedding was utilized in order to capture the multiple flow and combustion physics occurring all at once.

- Overall, the Omega type piston head configuration gives better performance as compared to the Open W counterpart.

- The fundamental reason for the better performance was found to be the greater spray penetration length of the Omega type head which is visualized using the bowl swap technique with the aid of modeled spray parcels.

- The only downside of the Omega piston head configuration would be its higher $\mathrm{NO}_{\mathrm{x}}$ concentrations.

- The same computational model may be extended for simulating the combustion chamber of a gas turbine engine at the most part, with minor adjustments.

\section{REFERENCES}

1. Jasak, Hrvoje \& Luo, J. \& Gosman, A. \& Echtle, H. \& Liang, Z. \& Wirbeleit, F. \& Ag, Daimler-benz \& Wierse, M. \& Rips, S. \& Werner, A. \& Fernstrom, G. \& Karlsson, A.. (2000). Rapid CFD Simulation of Internal Combustion Engines. 10.4271/199901-1185. 
2. Raj, M. \& Sairam, C. \& Abdullah, J.. (2016). Analysis on IC engine performance using CFD. Advances and Applications in Fluid Mechanics. 19. 829-836. 10.17654/FM019040829.

3. Saddique, Abdul \& Azeez, Shaik \& MOHAMMED, RAFFI. (2016). Simulation And CFD Analysis of Various Combustion Chamber Geometry of A C.I Engine Using CFX. International Refereed Journal of Engineering and Science (IRJES). 5. 33-39.

4. Zhu, Y. \& Zhao, Hua \& Melas, D. \& Ladommatos, Nicos. (2004). Computational Study of the Effects of the Re-entrant Lip Shape and Toroidal Radii of Piston Bowl on a HSDI Diesel Engine's Performance and Emissions. 10.4271/2004-01-0118.

5. Dawat, Vamshi Krishna \& Ganesan, V.. (2015). Effect of Swirl Ratio on Combustion and Emissions with a Re entrant Piston Bowl in a DI Diesel Engine.

6. Reitz, Rolf \& Diwakar, R.. (1987). Effect of drop breakup on fuel sprays. SAE Paper. 3218-3227.

7. Vedagiri, Praveena \& Martin, Leenus \& Varuvel, Edwin. (2019). Characterization study on performance, combustion and emission of nano additive blends of grapeseed oil methyl ester fuelled CI engine with various piston bowl geometries. Heat and Mass Transfer. 56. 10.1007/s00231-019-02740-9. 
